\title{
Immunohistochemical localization of hTERT protein in oral carcinogenesis
}

Type: Meeting abstract

\section{Content:}

Introduction: Human telomerase reverse transcriptase (hTERT) the catalytic subunit of telomerase is associated with cellular immortalization and tumorigenesis .In situ detection of hTERT using immunohistochemistry (IHC) allows localizing the hTERTpositive cells and also overcomes the limitation of requirement of fresh tissues for molecular techniques such as Telomeric Repeat Amplification Protocol (TRAP) for telomerase/ hTERT detection. The objectives of this study are to detect hTERT protein expression using immunohistochemistry in different histological stages in oral carcinogenesis with paraffin embedded tissue samples and cultured cells and to relate the hTERT expression with different histological stages in oral carcinogenesis. Materials and Methods: A total of 41 parafin-embedded tissue samples with histological diagnoses of normal oral mucosa $(n=5)$, epithelial hyperplasia $(n=5)$, mild epithelial dysplasia $(n=9)$, moderate and severe epithelial dysplasia $(n=8)$ and oral squamous cell carcinoma (OSCC, $n=14$ ) were analysed for hTERT protein using IHC. TRAP assays were performed on cultured cells namely fibroblasts (immortalized with hTERT) and keratinocytes (OSC-20, OSCC cell line, H S R R B, Japan) as positive controls. The hTERT- labelling index was determined following previously published criteria. Results: All the tissues showed Grades 3 \& 4 staining ( $>10 \%$ positive staining nuclei) in basal and parabasal cell layers which are the normal proliferative progenitor compartments where hTERT expression is considered normal. hTERT expression in the superficial layers of the epithelia was elevated in moderate and severe dysplasia (75\%) with Grades 3 \& 4 staining, reduced in mild dysplasia (33.3\%) and with no expression in epithelial hyperplasia and normal oral mucosa. hTERT protein expression correlated with positive telomerase activity in the cultured cells. Conclusion: There seems to be an up-regulation of hTERT expression with the progression of oral cancer and therefore indicates the feasibility of IHC detection of hTERT protein as a potential prognostic marker in oral carcinogenesis.

\begin{tabular}{|c|l|}
\hline Author & $\begin{array}{l}\text { Kumar, S. ; Ismail, S. M. ; Zain, R. B. ; Abraham, M. T. ; } \\
\text { Cheong, S. C. }\end{array}$ \\
\hline Source & Oral Oncology \\
\hline ISSN & $1368-8375$ \\
\hline DOI & $10.1016 /$ s1744-7895(05)80280-9 \\
\hline Volume (Issue) & $1(1)$ \\
\hline Page & $114-115$ \\
\hline Year & 2005 \\
\hline
\end{tabular}


Keyword:

Oral squamous cell carcinoma, OSCC, lichenoid lesions, lichen planus, oral cancer, oral tumours, pemphigus, traumatic eosinophilic granuloma, aphthous ulcers, oral mucosal lesions, betel chewers mucosa, betel quid related lesions, betel quid, areca quid, tobacco quid, oral cancer screening, training and calibration, early detection, oral cancer awareness, biobanking, tissue bank, databank, oral cancer, tissue bank, research credibility, research ethics

Please Cite As:

KUMAR, S., ISMAIL, S. M., ZAIN, R. B., ABRAHAM, M. T. \& CHEONG, S. C. 2005. Immunohistochemical localization of hTERT protein in oral carcinogenesis. Oral Oncology, 1, 114-115.

URL:

- http://apps.webofknowledge.com >>Search Via Web of Science Accession No: 000234494900276

- http://www.sciencedirect.com/science/article/pii/S1744789505802809 